\section{CONDICIONES Y CONDICIONAMIENTOS DE LA INNOVACIÓN SOCIAL}

\author{
Ander Gurrutxaga Abad \\ Catedrático Sociología. Universidad País Vasco \\ ander.gurrutxaga@ehu.es
}

\begin{abstract}
The concept of innovation has conditions and specifications that limit its' space of action. The most important conditions are those related to social change, the limits of social structures in knowledge societies, the limits in the culture of some social groups and the relations between diverse situations, their praxis and the rethoric that sometimos transform the concepto of innovation into a container concept.
\end{abstract}

KEY WORDS: Innovation; change; limits; conditions; possibilities.

\section{INTRODUCCIÓN}

A lo largo del texto me interesa indagar en las condiciones estructurales que crean/construyen/producen los lugares donde se celebra la emergencia de entornos innovadores. Mi hipótesis es que éstos están relacionados con espacios geográficos que aglutinan recursos específicos, condiciones socio-estructurales concretas que se anclan en ciudades donde la heterogeneidad se vuelve progresivamente hacia la búsqueda de la singularidad y de la narrativa que explica el trayecto por la sociedad del conocimiento. No niego con esta propuesta la importancia de otros enfoques para comprender la emergencia histórica del valor de la innovación, pero sí sostengo que ésta está asociada: 1) al juego de lo micro representado por la idea del emprendedor, cuestión sujeta a debate donde la ubicación del individuo y de los procesos de individualización, el diseño institucional adecuado para su emergencia y control y el papel de la sociedad, aparecen en los escenarios como la garantía de que las expectativas del motor de la innovación (el individuo creativo) y sus oportunidades no se mueven sobre escenarios comunes ni se transportan como la misma aceleración, ni probablemente circulan por carriles contiguos. 2) Las propuestas de lo meso donde la cultura requiere nuevos escenarios y nuevos valores para sedimentar la necesidad de ser necesaria donde: i) la cultura social asociada
CONDITIONS AND CONDITIONING FACTORS OF SOCIAL INNOVATION

RESUMEN: La innovación tiene condicionamientos y condiciones que limitan los espacios de actuación. Entre los más importantes están la relación con el cambio social, las limitaciones de la estructura social en las sociedades del conocimiento, los límites de la cultura de algunos grupos sociales, la relación con diversas situaciones, su praxis y la retórica con la que, a veces, la envuelven transformando el concepto en un contenedor.

PALABRAS CLAVE: Innovación; cambio; limites; condiciones; condicionamientos; posibilidades.

a las ideas de bienestar y calidad de vida, converge con; ii) la emergencia de una ética para el capitalismo líquido donde la ética se refugia en los valores que contiene a la clase creativa, los analistas simbólicos o los gestores del conocimiento; $y$, iii) la comunidad que acoge e inserta los procesos en ámbitos sociales y da cobertura a los recursos económicos que se movilizan en los lugares que celebra los entornos creativos. 3) Macro donde los elementos claves dependen de: i) las políticas de innovación que segregan los diferentes niveles gubernamentales; ii) las fuentes y formas de la financiación especialmente de la regulación del capital riesgo, de las inversiones del sector privado y del cuadro de subvenciones públicas; y iii) del sistema educativo, especialmente de sistema universitario y de los centros de investigación dependientes de las autoridades públicas de la región o del pais en concreto.

Los niveles micro, meso y macro se descubren como elementos con autonomía propia, pero sobre todo se denotan en sus interrelaciones e interconexiones. El resultado es la constitución de las condiciones necesarias para que emerjan y se consoliden los entornos socio-estructurales de la innovación, pero también los condicionamientos y límites que propician y generan. El análisis de los entornos y sus posibilidades quedan limitados sino analizamos los condicionamientos que señalan los límites de la innova- 
ción, por no citar al ausente recurrente de este análisis; las innovaciones que no sólo están ocultas (NESTA) sino las que quieren ser y fracasan. El fracaso debiera ser y debiera formar parte del catálogo de situaciones que analizan los entornos creativos, pero de momento lo dejaremos fuera de este artículo.

\section{La PRESENTACIÓN dE LA INNOVACIÓN}

Hay mucho que decir alrededor del concepto de innovación. Citar la palabra o manejar el concepto significa reconocer que, como dice X. Ferrás", "sin duda forma parte de la cartera fundamental de valores del siglo XXI". Se acercan a él desde perspectivas y prácticas diversas. P. Drucker ${ }^{2}$ decía que "la innovación es un trabajo racional, premeditado, sistemático y organizado". M. Porter ${ }^{3}$ lo refiere como un elemento de competitividad empresarial de los países. Estamos ante un concepto que tiene un largo recorrido ${ }^{4}$, por más que en las últimas décadas se asocie a los universos económico y tecnológico ${ }^{5}$ y a la metodología para la acción pragmática que emprende, por ejemplo, la Unión Europea y cuyos resultados visibles son el Manual de Frascatti ${ }^{6}$ y el Manual de 0 slo $^{7}$-en sus diferentes versiones-, seguidos en otros continentes por otras iniciativas como el Manual de Bogotá ${ }^{8}$. Asimismo, la institucionalización de su análisis y su praxis tiene interlocutores con la aparición de agencias gubernamentales y organizaciones como la Young Foundation en Gran Bretaña, NESTA en Gran Bretaña, CRISES en Montreal-Canadá, etc.

El universo empresarial enfrentó las dudas sobre la "empresa que viene ${ }^{\prime \prime 9}$ a través del énfasis puesto en la gestión, las formas de organización, la creación de la cultura organizativa basada en formas de autoayuda y comunicación, prestadas en parte, por la psicología que hereda del espíritu de Elton Mayo ${ }^{10}$ y la creación de valores y figuras ideales sobre las cuales referenciar la acción empresarial, como, por ejemplo, las ideas de emprendedor, sujeto creativo, compromiso o confianza. La llegada -ya en el siglo XXI y después de la debacle de grandes empresas como la norteamericana Enron- de la responsabilidad social empresarial o la incorporación de cuestiones (ahora transformadas en discurso performativo y narrativa empresarial sobre los valores que fomenta el capital social), permitieron a la empresa sumergirse, sin demasiados costes, en la inercia que le presta la asunción del cambion y el capitalismo líquido ${ }^{12}$. El encuentro, cuando no la creación específica de la idea, estaba "servida".

Las ideas y la praxis del carácter social de la empresa, la persecución de la sostenibilidad o el recurso a valores permitió, no sin contradicciones y paradojas, asumir dos planos, que en principio mantenían lógicas diferentes; i) el de la razón pragmática empresarial, basada en la búsqueda del beneficio económico, la competitividad, la productividad y las reformas internas ${ }^{13} y$; ii) el referido a valores asociados a la reconstrucción/reapropiación de la tradición weberiana de la ética en los negocios ${ }^{14}$. Algunos aspectos de las nuevas doctrinas del management acuden en su auxilio, leyendo la realidad desde las bases programáticas que presta el pensamiento posmoderno, y trasladando a la organización la trascendencia de los valores, la cultura y los contenidos que deben formar parte del código corporativo de la empresa. La llamada a los valores arraigados en la cultura empresarial como el esfuerzo, la dedicación o el compromiso se le suman la creatividad, la asunción de riesgo, la confianza, el respeto y la metamorfosis del cambio, hasta tal punto que la conclusión es que los únicos referentes fijos de la empresa son el cambio y la innovación. Esta última se transforma en la narrativa que a la vez es meta de llegada y salida, objetivo e instrumento de la mutación.

Las ideas de Schumpeter ${ }^{15}$-destrucción creadora- o P. Drucker ${ }^{16}$-la verdad de la innovación es la gestión-, son recopilados en la pragmática empresarial. La innovación, en estos casos, tiene poco que ver con los recursos tradicionales auspiciados desde la teoría económica, la teoría de la organización de la sociedad industrial o la teoría social del cambio. Llegados a este puerto, las rutas navegables señalan que la innovación es el instrumento que es a la vez un objetivo, meta, aspiración, razón pragmática, valor y apuesta por el cambio. Lo envuelve todo para cimentar lo que podría denominarse la razón pragmáticoinnovadora.

A lo largo de este tránsito, la psicología, a través de las diversas escuelas de ayuda mutua o de la psicología de la comunicación y la personalidad ${ }^{17}$, junto con instrumentos como la inteligencia emocional, la empatía, la comunicación y la creatividad legitiman el cambio de paradigma que sostiene la razón pragmática y lo transforman en 
razón innovadora. Los sujetos son el "nuevo empresario" y el trabajador que asocia el destino a los de la empresa. Los grandes ignorados son el contexto social y la sociedad genérica, como si la recuperación de la innovación pudiese licuar los contextos sociales y la sociedad como garantía de la metamorfosis. El resultado es un cuadro plagado de paradojas donde algunos aspectos de la narrativa tienen éxito y otros se transforman en la retórica de la narrativa.

El lugar más cómodo de este proceso está en manos del imperativo tecnológico que penetra en la empresa como el referente incuestionable de la mutación estructural, se transforma en referente y en el rostro incuestionado del valor de la innovación ${ }^{18}$. La vertiente tecnológica culmina el éxito de la revolución tecnológica en la industria por excelencia; las empresas TIC y las formas tecnológicas de vida ${ }^{19}$ que tiene en el dominio de Internet y en las redes sociales los soportes tecnológico y social, como si ambos compusiesen los rostros encantados del desencantamiento del mundo en la sociedad del conocimiento.

Para otras ciencias sociales, especialmente la sociología, la innovación no es un problema. La idea y la praxis se recoge en el análisis general del cambio social. La innovación es una de sus formas, recogida en los manuales clásicos de cambio como uno de los procesos relevantes junto, por ejemplo, y con similar estatus a la iniciación, difusión, terminación, descubrimiento o invención ${ }^{20}$. La cuestión sociológica no es pues el "olvido" sino la recepción a través de las interpretaciones del cambio, pero como un proceso del mismo. La obra clásica, por ejemplo, de R. K. Merton ${ }^{21}$ titulada "Teoría y Estructura Sociales", la estudia en el apartado dedicado a la estructura social y la anomia como un tipo de adaptación individual. En otro manual clásico posterior, "Sociología del Cambio Social"22 su situación no ha cambiado demasiado en relación de lo que ya indicaban las versiones clásicas. Quizá por eso, la sociología de la innovación se presenta, sobre todo, como el análisis específico y singular de uno de los problemas clásicos de la sociología; los procesos que impulsan el cambio. Éstos se asocian a las ramas especializadas de este conocimiento, las que se ocupan, sobre todo, de las consecuencias de las mutaciones materiales -tengan una u otra procedencia- para las sociedades; sean, por citar algunos de sus territorios más singulares, la institución trabajo, la organización interna de la empresa, las organi- zaciones sociales, los valores sociales, las formas políticas de gobierno o la cultura social.

La economía tiene antecedentes en el mercado que se abre con las tecnologías TIC y los soportes comerciales que emergen en el centro y en la periferia de las economías centrales globales ${ }^{23}$; conocimiento del funcionamiento de la institución por excelencia como es la empresa, relación con el impacto económico de los cambios auspiciados por la tecnología, capacidad para relacionar las condiciones para que las organizaciones económicas puedan cumplir las tareas asignadas y capacidad para asegurar el conocimiento experto que demanda la nueva situación. Ya no es la sociedad industrial la que hay que organizar ${ }^{24}$, tampoco en todos los casos, al menos, la sociedad tecnológicamente dirigida, pero sí un sistema productivo fundado en el conocimiento tecnológico y en los usos sociales del mismo, que requiere nuevas formas de entenderlo, nuevas maneras y nuevos contenidos, además de formas de organización que poco tienen que ver con el pasado fordista inmediato y sí con fórmulas entresacadas del debate de la empresa con la sociedad del conocimiento. Ésta rompe sus fronteras internas, se globaliza y encuentra en la desconfiguración de los límites y referencias el caldo de cultivo, caótico pero creativo ${ }^{25}$, donde las paradojas no son requisitos de los que hay que huir sino elementos que nacen de las contradicciones que hay que integrar en el marco de incertidumbre donde la búsqueda de la seguridad se transforma en elemento económico. La innovación -para la economía- no es un dato periférico sino central y básico para integrar en la dinámica material, aunque sea de forma caótica, los ingredientes que resultan de la revolución tecnológica y de la aplicación de la misma al proceso productivo y a sus productos.

La masiva influencia de Internet y las formas tecnológicas de vida, generan que la innovación sea el proceso que es más que un instrumento o procedimiento, se transforma en meta narrativa. La consecuencia es que la emergencia del análisis contemporáneo se asocia con procesos, agencias, agentes, ámbitos y dimensiones -micro, meso o macro- y en los discursos dominantes de la innovación definen un territorio difuso, incontrolado y lleno de saberes de distintas procedencias, que se refieren a individuos resolviendo problemas, a procesos en los que participan agentes, agencias y organizaciones que se anclan en espacios geográficos e institucionales de dimensiones diferentes, gracias a 
los recursos que encuentran en esos lugares ${ }^{26}$. Eso indica que el hecho innovador es posible en contextos socioculturales e institucionales donde comparte objetivos y crea redes de confianza, lealtad y conocimiento.

El resultado del proceso que acabo de presentar, me lleva a afirmar que hay que diferenciar tipos, ámbitos y dimensiones de innovación ${ }^{27}$; tecnológica, empresarial, institucional, política, social y/o cultural, que la innovación pasa por diversas fases, que se ancla en alguna de ellas y existen metodologías para canalizarla según el campo de acción, el ámbito o la dimensión donde se inserte.

Desde mi perspectiva está ligada a seis hechos; 1) a situaciones, ámbitos, dimensiones, agentes y agencias significativas. Emerge en diferentes campos; en la economía, la sociedad, las administraciones públicas, los servicios sociales, las actividades de sanidad, la praxis de la tercera edad, el ocio y otros acontecimientos relacionados con diversos ámbitos sociales. 2) Es pragmática y funcional, persigue objetivos y diseña programas específicos basados en la idea de buenas prácticas. 3) Tiene connotaciones éticas que se relacionan con valores como la creatividad, el respeto, la atención, la confianza, la lealtad o la responsabilidad. Los postulados se asocian con la dimensión ética de las acciones económicas, el mundo de los negocios, las organizaciones de la vida pública y la sociedad civil. 4) Orientación metodológica, como si el éxito dependiese de la capacidad para gestionar procedimientos y buenas prácticas. 5) Se presenta como discurso y meta narrativa. El aparente "estar en todas partes" es el producto del diálogo entre dos de las fuerzas que conforman el presente; la incertidumbre y el cambio. 6) Los discursos que emergen se asocian con la comprensión del cambio y se representan como prácticas avaladas por procesos que abandonan los lugares donde se representan (los universos empresarial y tecnológico) para penetrar en otros rincones de la acción social.

La pragmática de la innovación, tal y como queda defini$\mathrm{da}$, contiene contextos y condiciones, condicionamientos y límites. El resultado es que, en muchos casos, son difíciles de asumir algunos de los problemas y paradojas que se gestan en nuestras sociedades, sea porque: i) el mundo económico-empresarial encuentra límites para crear innovando; ii) por debilidad en las inversiones económicas; iii) por que falla la oportunidad, la creatividad o el déficit de conocimiento de cómo funciona el proceso innovador, cuáles son las fuentes o el papel de clientes y usuarios ${ }^{28}$; iv) en otros, los orígenes son estructurales; entre las expectativas generadas y las oportunidades creadas hay un desajuste imposible de reducir; v) en algunos momentos, pese a la insistencia en la capacidad creativa del individuo y de su papel en la estructura laboral, ésta no es ni lo clara ni nítida que se supone ¿por qué? porque la lealtad, la confianza y el conocimiento institucional son herramientas difíciles de alcanzar ${ }^{29}$ por más que en su auxilio acuda la praxis de la responsabilidad social empresarial, el capital social, los planes de calidad u otros incentivos. El resultado es que la relación entre el individuo, el trabajo y la empresa no está clara ${ }^{30}$; vi) otros peligros vienen de los procesos de cambio en las empresas. El tránsito desde definiciones fordistas a otras más abiertas - soft o light ${ }^{-31}$ demuestran que la empresa, el empresario, los productos, el trabajador, el cliente, el ciudadano o el consumidor no son lo mismo que en décadas pasadas ni representan los mismos papeles.

\section{LAS CONDICIONES DE LA INNOVACIÓN}

La innovación nombra lo que ocurre en la historia de la humanidad ${ }^{32}$ : sabemos que experimentamos con actividades materiales, culturales y simbólicas y gestamos conocimiento de hechos y cosas que se transfieren a grupos e individuos. El cambio y las respuestas al cómo, por qué y para qué encierran cuatro hechos; comprender la experimentación de los humanos sobre su realidad, aprender a cómo se aprende -cómo dijo el lema que articuló J. Delors cuando se refirió al cambio educativo y creo el lema "aprender a aprender"-, crear nuevo conocimiento y transferirlo a individuos, grupos y sociedades. Los humanos innovamos adecuando las respuestas a viejos o nuevos problemas, adelantando el futuro y soñando con el control de lo creado ${ }^{33}$.

La innovación está ante esta encrucijada de problemas. Promueve y aprovecha el cambio, lo vive como oportunidad, sabe que debe acercarse a entender y gestionar sus consecuencias, algunas previstas y otras no, conocidas pero no deseadas. El carácter poliédrico y la gestión de los ámbitos, dimensiones y circunstancias promueven que se parezca al contenedor donde caben situaciones diferentes y perchas de la que puedan colgarse prendas distintas. Es- 
tas situaciones tienen que ver con los cambios que asume, con la praxis que gestiona, el manejo de la incertidumbre y los requerimientos de "lo nuevo" ante la entrada a una era - confusa, indefinida, con suficientes turbulencias como para cerrar análisis o categorias heurísticas, pero ante la que hay que estar atentos, abiertos y asumir las paradojas que se afirman-.

El peligro es que la innovación sea acogido, permítaseme la licencia narrativa, como un concepto religioso en el que la creencia y la fe en ella estén por encima de las virtudes empíricas, como si fuese la profecía autocumplida donde sus condiciones nunca se hubiesen comprobado empíricamente porque o no hiciese falta hacerlo o no fuese suficiente para descargarles de la responsabilidad por utilizar el concepto o imaginar y trabajar bajo ese imperativo.

Un panorama visual sobre la situación de la innovación es el que presenta el mapa elaborado por la consultora Mackinsey ${ }^{34}$. Sus autores lleva a cabo, después de haber construido y analizado 700 indicadores y haberse orientado construyendo tres figuras conceptuales (denominadas apuestas heroicas, ofertas irresistibles, conocimiento oasis) -a las que no sé si podemos calificarlo de tipos ideales, seguramente no en el sentido weberiano-, un dibujo sobre la situación del mundo y sobre cómo ver en él la perspectiva de la innovación.

Probablemente una de las cosas sugerentes de ese tipo de mapas es que nos cuentan de otra manera lo que ya sabemos. Ciertamente, nadie acostumbrado a leer índices e indicadores puede esperar grandes sorpresas de este tipo de mapas. Sabemos que si analizamos la información que aportan -cito sólo algunos de los conocidos-; el índice de Desarrollo Humano, el Informe PISA, la inversión de los países en $\mathrm{I}+\mathrm{D}+\mathrm{i}$, transparencia internacional, los ranking universitarios, podríamos trazar mapas nuevos e incluso si pudiésemos montar unos encima de otros, probablemente habría algunas coincidencias.

Una y otra situación permiten ver las tensiones que animan el escenario global en lo referido a las condiciones para construir entornos innovadores. Estas tensiones las recuerda, y cita con precisión, el presidente de la Comisión Europea -J. M. Barroso- en el informe de 4 de febrero de 2011 titulado "Prioridades de Europa en materia de Innovación" ${ }^{35}$, cuando advierte que "Europa corre el peligro de perder terreno, y en páginas sucesivas compara los resultados de la UE con los de EE.UU., Japón y China, para pasar a reconocer que poco a poco, la UE se está quedando rezagada en I+D porque efectivamente aunque Europa cuenta con innovadores de primer nivel, los resultados varian de un país a otro. Lo que falla en Europa, según el informe presidencial -probablemente remedo de otros anterioreses la poca disponibilidad financiera, patentes caras, falta de condiciones jurídicas y fiscales equitativas, normativas y procedimientos obsoletos, lentitud en la adopción de normas, debilidad de los sistemas de educación pública y de innovación, falta de uso estratégico de la contratación pública y fragmentación de esfuerzos.

La pregunta, después del diagnóstico, parece pertinente: ¿qué podemos hacer? El texto del presidente responde con cuatro medidas generales; saneamiento fiscal inteligente, mejores condiciones generales, dirección y supervisión a escala de la UE y un presupuesto de la UE que mire al futuro. Obviamente, formuladas las cuatro medidas generales "hay que bajar a pie de obra" y responder por cada una de ellas; respecto a la primera concluye que las actuales presiones financiera y fiscal podrian llevar a recortes en I+D e innovación, en consecuencia se precisa de un saneamiento fiscal riguroso y unos gastos que favorezcan el crecimiento, pese a todo hay estados miembros que están consiguiendo mantener o incrementar sus inversiones públicas en innovación e I+D. Para la segunda -mejores condiciones generales- consiste en la creación de un verdadero mercado a escala UE para fondos de capital riesgo, adoptar medidas con respecto a los derechos de propiedad intelectual, compartir la excelencia en ámbitos de interés social, adopción más rápida de normas europeas, mejores prácticas en materia de contratación pública. El cuadro de oportunidades continúa abierto cuando sigue explicitando la prioridad -dirección y supervisión en la UE- y reclama un papel claro del Consejo Europeo para dirigir los avances, utilizar como referencia el objetivo general del $3 \%$ en I+D, las formaciones del Consejo deben ocuparse de la Unión por la Innovación, completar el Espacio Europeo de Investigación para 2014, acordando la plena movilidad de los investigadores y atraer nuevos talentos. La financiación de todo esto puede resolverse si se elabora un marco estratégico común para mancomunar los recursos y facilitar la programación conjunta, impulsar fuentes de financiación innovadores y simplificar trámites. 
El discurso de Barroso no es nuevo. Podríamos buscar antecedentes en los últimos años ${ }^{36}$. Lo que nos permite -de aquí el interés del documento- es ver cómo la innovación se asocia a la creación de entornos socio-estructurales adecuados, entornos -denominados- innovadores para unos y creativos para otros ${ }^{37}$. Cuando analizamos las condiciones de la innovación hay una narrativa que se construye en cada caso. El origen comienza cuando se ocupa un lugar significativo en el mapa y este lugar aparece como referencia en los canales informativos al respecto, para posteriormente trazar el itinerario hacia atrás e ir recordando como se llegó a ser para y sobre todo, tomar un camino ejemplar e indicar a los demás cómo se puede llegar a ser. En cada fase y en cada etapa se presenta en competencia con otros casos y otras formas de hacer, es decir, siempre hay referentes a los que mirar, imitar o difundir. La conclusión es que no basta con ser, hay que ser junto a alguien y/o frente a alguien.

Las preguntas que definen las estrategias son las siguientes: ¿cómo puedo llegar?, qué tengo que hacer para ser? y ¿cómo ser para seguir estando? Mi hipótesis es que los denominados entornos de innovación son el producto de las respuestas que se dan a las cuestiones citadas. La innovación es el marco donde las preguntas se pueden hacer, el objetivo y la meta, condición y narrativa que cuenta, explica, explicita y legitima por qué hay que ser innovadores y debe aceptarse el marco de referencia. La narrativa cuenta y define la forma de ser y estar en el mundo -por cierto, quizá no muy distinta a la que sugirieron las teorías de la modernización ${ }^{38}$-. Ciertamente, la globalización acabó con esta posibilidad y puso en marcha el turbo en el que vivimos ${ }^{39}$.

En la situación que visualiza el mapa, los entornos y las condiciones que lo hacen posible no dejan fuera a nadie que quiera o pueda estar; desde luego, la globalización construye nuevas condiciones y excepto para algunas zonas del mundo, la mirada innovadora no se posa sólo en los lugares de vieja industrialización, los viejos imperios sino que están quienes pueden estar. Los mapas definen un nuevo "hogar", "nuevas posadas" pero, sobre todo, comprimen la historia, transforman el pasado en el presente que mira al futuro ${ }^{40}$, de tal manera que lo único que importa no es lo que has hecho, ni el lugar del que partes, sino lo que haces o puedes hacer en ese momento. Los entornos creativos juegan con la historia, lo hacen para disolverla en sentido tradicional, la historia es, sobre todo, la realización del presente. La densidad de los entornos creativos no excluyen la clasificación interna ni la posibilidad de elegir donde puedes estar. El drama de los entornos innovadores es que la exclusión forma parte del juego clasificatorio; incluso no se necesita -habitualmente porque no se puede- estar en el centro e invertir una parte sustanciosa del PIB en I+D+i, lo que te aleja y "expulsa" es no estar, luego se puede estar de diferentes maneras, lo "que no se debe es no estar".

Los entornos creativos definen espacios relevantes, espacios que desde la confrontación, la imitación y la difusión componen y describen los recursos necesarios para construir y mantener lo que tanto los mapas de innovación como el presidente Barroso describen. En el caso de los entornos innovadores, los casos convertidos en tipos ideales aportan información. Diría más, se transforman en las guías del cambio. De su estudio emerge el conocimiento experto que se transfiere a otros lugares, siguiendo la difusión en la imitación del modelo referente. Esta idea es evidente cuando, por ejemplo, tantos análisis ponen sus ojos en el referente Sillicon Valley, la ruta 121 en Boston, el caso finés, las singularidades de Singapur, Japón o Corea del Sur o en los últimos años el caso de China ${ }^{41}$. Paradójicamente, los secretos de cómo hacerlo son públicos, la confidencialidad dura lo que la red tarda en penetrarlos y la competencia en dejarlos obsoletos. Es curioso, por ejemplo, cómo en las clasificaciones de patentes o en las inversiones en $\mathrm{I}+\mathrm{D}+\mathrm{i}$-tanto en sociedades como en empresas- se suceden países o empresas que suben o bajan, se juegan el prestigio y lo que es más importante, la competitividad, la productividad y la posición en el mundo dependiendo del lugar.

Visto lo visto, parece que la innovación hay que entenderla desde la definición de la situación ${ }^{42}$, sabiendo que está condicionada por los ámbitos donde actúa, los requerimientos y las dimensiones que quiere alcanzar. En todo caso, del análisis de los procesos concretos parece desprenderse la tesis, después de mirar los mapas y cruzar los resultados con los procesos y las singularidades históricas que los avalan, que la mirada empírica advierte que no existe una receta universal que explica las razones de la emergencia de la innovación. Antes al contrario, los hechos conceptualizan el mosaico de experiencias que en muchos casos no pueden extrapolarse unas de las otras, 
pero en todos aparecen indicadores y variables presentes en muchos casos. Esto permite tipologizar los modelos para comprender los procesos que genera.

Teniendo esto en cuenta en los contextos de innovación pueden dibujarse tipos preferentes, según la forma en que organizan la relación entre: i) las regulaciones y funciones que se atribuye el Estado; ii) el papel del mercado; iii) la regulación e inversión financiera; iv) el sistema y el diseño institucional del que se dotan esos espacios; v) las instituciones e infraestructuras construidas para favorecer la transferencia de conocimiento; $y$, vi) la cultura de la innovación que pueda crearse.

Si, por ejemplo, uno de los modelos se visualiza en Sillicon Valley ${ }^{43}$, es porque aporta la idea del valor del individuo emprendedor, la necesidad de construir espacios de investigación y de gestión del conocimiento en entornos geográficos donde llega la iniciativa individual, hay buenos centros universitarios, recursos de investigación ubicados en lugares geográficos estratégicos, inversiones privadas, capital riesgo, subvenciones públicas y contratos de origen tanto públicos como privados. En cambio, el modelo nórdico -como han contado M. Castells y P. Himanen ${ }^{44}$ se construye desde el pacto originario entre los emprendedores - la universidad- la empresa y la administración pública, contando con el desarrollo del Estado del bienestar y la capacidad de las ideas para componer los horizontes de futuro. En el caso de los países del Sudeste Asiático ${ }^{45}$, y dejando al margen las singularidades de cada uno de ellos, la acción estratégica del Estado es el factor más importante para comprender el desarrollo de las sociedades y de los procesos de innovación.

Lo que de los análisis citados se desprende es que los mapas de innovación se incardinan en contextos socio estructurales, éstos tienen especificidades que hay que tener en cuenta, porque, por ejemplo, la estructura industrial de los países no es la misma ni lo son las oportunidades de negocios. La globalización abre el mundo y desplaza el cuadro de oportunidades hacia el Este, el Sur, el Oeste y el Norte, de tal forma que la geografía de oportunidades encuentra otros puntos y otros nodos para establecer sus expectativas. En general, los factores citados se encuentran con experiencias y procedimientos que sintetizan el mapa de innovación, es decir, el nivel educativo es importante, lo son las condiciones legales que facultan la libertad de innovar, la creatividad cultural, los diseños institucionales creados para fomentar la investigación y el mercado del descubrimiento, la financiación de los proyectos empresariales, la logística e infraestructuras y la conexión a redes.

Los mapas detectan otro fenómeno singular ${ }^{46}$. Los espacios de innovación tienden a concentrarse en territorios de carácter urbano-metropolitano. ¿Por qué ocurre esto?, porque en ellos se dan las condiciones que propician la emergencia de lugares y prácticas innovadoras como son la acumulación de soporte técnico, recursos humanos cualificados, infraestructuras tecnológicas, universidades, centros de apoyo, capital riesgo, proximidad espacial o la concentración de diferentes agentes y recursos, entre otros ${ }^{47}$.

El fenómeno relevante se asocia con la emergencia de una ciudad, cuya fotografía la presenta como una forma urbana dispersa de forma, de escala regional y compleja en su organización. Como explica el geógrafo E. W. Soja ${ }^{48}$, lo urbano se reconduce hacia un modelo de organización policéntrica, fragmentada y discontinua, confusa y con el variado y cambiante reparto de funciones entre la parte interior y la parte exterior. El sociólogo francés F. Ascher ${ }^{49}$ señala y nombra la metápolis como la mejor forma de definir la realidad urbana. Son conurbaciones extensas, discontinuas y heterogéneas, donde el crecimiento de la aglomeración da paso al crecimiento externo, es decir, a la absorción de ciudades y pueblos cada vez más alejados del centro original. Los ciudadanos se desplazan mucho y más lejos con lo que se transforma el sistema de movilidad urbana. Por otra parte, las telecomunicaciones modifican el sistema de movilidad urbana de bienes, información y personas y crean nuevas estructuras espaciales o, como dice S. Sassen ${ }^{50}$, incluso los sectores informáticos avanzados poseen un proceso de producción ligado al menos en parte, al territorio, ya que -aunque sus productos sean hipermóviles- requieren una combinación de recursos determinados. Los espacios son lugares que se comunitarizan e individualizan por igual, las personas viven en el espacio-tiempo transversal y utilizan los medios técnicos para incrementar la autonomía personal, desplazarse y comunicarse, sea en los medios de transporte o los objetos portátiles -especialmente el teléfono móvil-51. Estamos ante ciudadanos que viven la relación con el medio físico y social mediatizados, como explica S. Lash ${ }^{52}$, por las formas tecnológicas de vida. Esto quiere 
decir que hacer es conocer, que las formas de vida son rápidas, la cultura es efímera, la velocidad impone su lógica y se somete a la regla de oro de la obsolescencia. El futuro lo invade todo y la nueva generación no es la de hoy sino la que aún no es. Las formas dependen de la organización en red.

La sociedad red ${ }^{53}$ está formada por flujos, comunicaciones y transporta información, pero como detecta S. Lash ${ }^{54}$, en una teoria muy atractiva sobre las zonas geográficas e identitarias en la ciudad, la determinación de las clases sociales puede relacionarse menos con una ubicación en la producción que con una ubicación en el espacio, y puede ser, en especial, un asunto de zonas. En su enunciado destacan cuatro zonas; cuando los flujos son pesados, hay zonas vivas. Cuando son relativamente livianos, zonas muertas. Cuando los flujos tienen densidad elevada, zonas domesticadas. Cuando esa densidad es menor, zonas silvestres. Pero, las zonas vivas y las zonas muertas no se superponen exactamente con las zonas domesticadas y las zonas silvestres. La descripción de estas cuatro zonas permite a Lash trazar un mapa para ubicar formas sociales de ocupación de los espacios físicos y de los espacios identitarios de la ciudad. El juego de las cuatro zonas permite entrever como se cruzan unas y otras o cómo se mueven, creando un mosaico de posibilidades donde lo vivo y lo muerto se cruzan con identidades domesticadas o silvestres.

Tras las ideas de M. Castell ${ }^{55}$ sobre la ciudad informacional, las descripciones de los contextos urbanos dan importancia al impacto provocado por la revolución de las tecnologías de la información y la comunicación. El acento en las infraestructuras digitales, los sectores industriales de alto valor tecnológico, los servicios ricos en información tecnológica y en la aparición de grupos sociales asociados a estas características -que R. Reich ${ }^{56}$, por ejemplo, denomina analistas simbólicos-, ven el hábitat urbano compuesto por ciudades conectadas mediante redes digitales, cuyo desarrollo se basa en el uso intensivo de las tecnologías de información y comunicación, combinando la infraestructura digital con el crecimiento que se aplica a la mejora de la calidad de vida y el trabajo de sus ciudadanos ${ }^{57}$, como espacios de información y comunicación, en los que las TIC se integran en entornos de vida y trabajo y la creatividad individual con las estructuras digitales que facilitan la gestión del conocimiento ${ }^{58}$.
Según Winden, Van Berg y Pol ${ }^{59}$, siendo la producción de conocimiento el motor principal del desarrollo y el crecimiento de las zonas vivas de las ciudades, los éxitos relativos se evalúan en función del número de patentes y gasto en I+D+i. En este marco, los sistemas urbanos están diseñados para aprovechar las sinergias que generan los contextos tecnológicos. La conclusión es que la innovación necesita de contextos adecuados y terreno donde cultivarse. El resultado es que el éxito es una cuestión relacionada con la cultura compartida, el dinamismo de las redes de transferencia de conocimiento y con los elementos que facilitan el intercambio de información entre los que son diferentes.

El trabajo de un conjunto de historiadores ${ }^{60}$, avala esta tendencia al demostrar que la construcción del tiempo global es el impulsor de excepcionales innovaciones a gran escala capaces de transformar las estructuras socioeconómicas del planeta. Tanto la revolución neolítica, la revolución científica como la revolución industrial y las transiciones actuales hacia las sociedades del conocimiento, son el fruto de la creación de redes que conectan entre si pueblos, ciudades y personas, transfiriendo información, conocimiento y gestando interdependencia, de tal suerte que el resultando es la interconexión de las diferentes partes del mundo.

La conclusión es que el estudio y la praxis de la innovación demuestran que los mapas ofrecen la perspectiva de un edificio sin terminar, un laboratorio sin organizar del todo, que ofrece y pone a disposición de agentes sociales y sociedades un mapa de navegación y rutas que señalan por donde se debe caminar si se desea estar, es decir, qué hay que hacer, o dicho de otra manera, qué es lo razonable para alcanzar lo que se persigue.

\section{Condicionamientos de la innovación}

Después del recorrido propuesto voy a referirme a algunos de los problemas -los denomino condicionamientos- que atraviesan los análisis de la innovación social. Pongo el énfasis en cinco de ellos.

1. La conceptualización de la innovación está afectada de algunas indefiniciones. El concepto está de moda 
-tal y como he hecho hincapié a lo largo de las páginas anteriores- y conlleva que se transforma en algo similar a un "recurso para todo". El peligro que veo es que el espacio analítico y teórico de la innovación quede tapado por la retórica, el orden de la simulación ${ }^{61}$ y que el papel de concepto contenedor ${ }^{62}$ rebaje las posibilidades teóricas, empíricas y analíticas.

2. Se tiene la impresión que hay un cierto olvido de los condicionamientos estructurales, materiales, como si estuviésemos ante "procesos ciegos" que se mueven siguiendo reglas donde los condicionamientos materiales y estructurales juegan un papel menor, cuando por el contrario, da la impresión que la estructura social y sus condiciones pesan mucho ${ }^{63}$.

3. Mientras que hay una interconexión entre innovación, sociedad del conocimiento y estructura social, a veces se pierde de vista que las transformaciones sociales están generando procesos donde muchos individuos quedan atrapados por la incapacidad estructural para disfrutar del mundo de creatividad y autotransformación que promete. En esa estructura social hay trabajadores cualificados -auto programados-, trabajadores genéricos ${ }^{64}$ y sectores sociales que viven con angustia la posibilidad de hacer realidad sus expectativas porque carecen de oportunidades.

4. Hay una peculiar forma de entender el cambio, como si siempre que ocurren procesos de innovación debiéramos escribir sobre transformaciones de ruptura, cuando en muchos casos lo que hace es apuntalar la continuidad y la transformación sin cambio. El origen está en la mala comprensión del cambio y en posiciones ideológicas alrededor de la respuesta a las preguntas sobre qué es la innovación.

5. Haria falta reinventar un nuevo lenguaje, una narrativa para comprender los sucesos que se mueven tras la innovación. Las fuentes del lenguaje teórico de la innovación están en la teoría social, la economía de la innovación y el conocimiento, las teorías del management y la psicología de la autoayuda y la comunicación. Las dudas proceden de la posibilidad de esos lenguajes para crear la cultura teórica de este fenómeno o si lo que se incorporan no es un lenguaje que, en ocasiones, da la impresión que permite asociar las necesidades empresariales con los signos de los tiempos y las transformaciones estructurales, pero que no permite comprender los sentidos de la innovación social.

\subsection{La Innovación y el concepto contenedor}

El primer hecho, tal y como he tenido oportunidad de poner de manifiesto en la primera parte de este artículo, es la multiplicación de sonidos - ruido- que reina alrededor de la utilización del concepto de innovación, así como, las paradojas que atraviesan los discursos y la praxis. Éstas afectan al carácter conceptual, de tal suerte que en ocasiones, no es fácil construir la explicación de por qué el concepto está tan usado que se encuentra con que es empleado para fines ajenos a su tradición ${ }^{65}$. Es frecuente también encontrar llamadas que creen que la innovación es el recurso, la llamada genérica al cambio y a aceptar la transformación. El resultado es el juego de espejos en los que se comprime la imagen para expresar que el presente es innovador, que en el pasado algo tuvo que ver la innovación y que el futuro no se comprende sin ella. Es, desde este punto de vista, una materia -sagrada para unos y profana para otros-, pero significada y repetida en círculos sociales, económicos, políticos y culturales, como si quién no estuviese dispuesto a aplaudir este espíritu no estuviera con los tiempos.

En todo caso, detecto tres peligros: i) la disolución objetiva del concepto provocada por el sobreuso, de tal manera que al ser tan abarcador resume tantas cosas que no discrimina lo suficiente o no aclara lo que debe, si se prefiere, no tiene carácter definidor y se refugia en la casuística de la retórica de la repetición, como si las llamadas continuas al mismo, o el hecho de ser pronunciado cuantas más veces mejor tuviese capacidad para forjar la realidad. El hecho conduce a que; ii) la innovación, en muchos casos, simula, esconde y cree tener aquello que no tiene. Recordemos que simular es aparentar tener lo que no se posee. En ocasiones, da la impresión que lo más importante es la narrativa, lo que se dice que es -habría que traer aquí a colación aquella frase de Spinoza cuando específica que "el concepto de perro no ladra", el que ladra es el perro-. El resultado del éxito es la creación de retóricas reiteradas y reiterativas que creen que por ser repetido el concepto es válido. En este caso se corre el peligro de terminar la misión antes de alcanzar playa segura, siendo sustituido 
su potencial empírico y analítico por su potencial retórico; iii) en ocasiones, no se tiene en cuenta la diversidad de ámbitos, las dimensiones diferentes, los procesos sobre los que transita, los mecanismos con los que se expresa, las agencias en las que se plasma y reproduce y los agentes que la protagonizan. Dicho de otra manera, la complejidad del proceso no puede ser sustituida por la retórica de sus excesos ni por la simulación del que decide vivir al margen del análisis empírico y la bondad analítica.

\subsection{Innovación y contextos sociales}

El segundo hecho lo provoca la "huida" que, en ocasiones, se aprecia del carácter estructural y condicionado de los procesos de innovación. Ciertamente, aunque no se sea escrupuloso en la lectura de los efectos de los procesos de transformación estructural, ésta conduce a la descripción de la situación material de las sociedades. Sabemos que cuando los paises se desarrollan económicamente y cumplen algunos requisitos como la redistribución de la riqueza, la creación de puestos de trabajo, movilidad social, grados razonables de bienestar, sistemas institucionales eficientes y eficaces, grados tolerables de corrupción 0 difusión de buenas prácticas, las sociedades son capaces de desarrollar culturas y tradiciones que conforman supuestos para apuntalar sistemas de innovación ${ }^{66}$. La hipótesis razonable indica que el éxito depende de la acumulación de innovaciones en todos los estadios de la sociedad-acumulativas o, en su caso, de ruptura-; en la vida económica, en los sistemas de protección ciudadanos, en la legislación social, en el funcionamiento del mercado, en el sistema educativo, en el sistema de salud, en el sistema institucional, en el Estado o en la vida cultural y social que se depositan en el transcurso del tiempo. En todo caso, si no se puede prever cuando un país alcanzará el desarrollo y el bienestar a "ciencia cierta", sin tener en cuenta la compleja combinación de factores históricos específicos de cada pais, cabe responder por qué se mantienen. La mejor respuesta que conozco es que perduran a condición de que mantenga cierto umbral de bienestar para los ciudadanos y que la riqueza material, las convenciones e instituciones sociales que las acompañan sean asumidas por la ciudadanía.

Los hechos deben ponernos sobre aviso para huir de las interpretaciones que desconocen el carácter imperativo de algunas de las reglas que rigen nuestro tiempo. Digo esto porque, en ocasiones, los procesos de innovación se presentan al margen de los condicionamientos estructurales y las reglas que marcan las tendencias del presente. Este olvido nos coloca en una vía analítica complicada, sobre todo si analizamos las dimensiones macro o meso. El análisis empírico, por ejemplo, de cómo construir procesos de modernización económica, social o política, cómo comprender las transformaciones auspiciadas por instituciones macro o meso, recuerdan que las innovaciones son procesos que aparecen condicionados por el poder de las redes y los intereses materiales que, en muchos casos, los condicionan y dirigen hacia lugares no previstos provocando consecuencias indeseadas. Del poder de los condicionamientos no queda fuera nada ni nadie, tampoco, por supuesto, la innovación social.

\subsection{La diversidad del cambio y recursos de la innovación}

La experiencia demuestra que los recorridos por los territorios que define el cambio llevan a pensar en su papel y en el de su alter ego; la incertidumbre. El final del siglo XX visualiza transformaciones sociales, económicas y la aparición de paradigmas que intentan entender el mundo que no se ajusta al creado por el orden social de posguerra; la globalización es el punto de llegada y salida porque interpreta el mundo, fusiona ideas y lo hace desde categorias como las de incertidumbre, riesgo, inseguridad, flexibilidad, precaución, competitividad, productividad, innovación, etc. Jugar al cambio nos introduce en la memoria histórica y nos atrapa en el mar de sus condicionamientos. De igual modo, si abordamos el recorrido por las fuentes del cambio, la innovación o la incertidumbre, la perspectiva no es la misma si nos alejamos de nuestros "frentes de batalla" y nos sumergirnos en la búsqueda de las consecuencias del análisis del cambio y vemos las claves del papel que asociamos a la innovación. Hay que diferenciar la definición univoca e incuestionable de lo que aporta, para analizar su praxis, es decir, las acciones que desarrollan o, dicho de otra manera, sigamos la innovación en sus praxis, ya que, al igual que ocurre con otros hechos sociales, el descubrimiento nunca es un fenómeno aprioristico que está ahí, fuera de la praxis y la acción humana, sino que se descubre cuando sus consecuencias transforman y mueven las respuestas que confirman el acto de innovar. Eso evita partir del hecho de que la innovación es consustancial a la naturaleza humana o a la sociedad que practica con ella. 
Nos cuenta D. Bell 67 en su libro "Las Contradicciones Culturales del Capitalismo" que la ética puritana inundó y dio cobertura ideática al triunfante capitalismo de producción. La fórmula, en la que Max Weber ${ }^{68}$ invirtió mucho talento, dota de "alma" a la naciente sociedad capitalista. Las ideas más sugerentes que introduce en la sociedad son: 1) que el trabajo es un deber y una vocación, -es lo que debe hacerse-; 2) la disciplina es temporal. El tiempo es "oro" -decía B. Franklin- es decir, expresado de otra manera, el tiempo es dinero. El tiempo está regulado por las condiciones de vida orientadas al trabajo. De esta forma, vida, trabajo y dinero aparecen encadenados, interdependientes unos de otros. El bien que la ética persigue es ganar dinero y obtener beneficios ${ }^{69}$. Eso garantiza el éxito en el trabajo y da valor a la representación que el capitalismo tiene de sí mismo. Ganar dinero no es algo que pueda rechazarse, sino por el contrario, es el imperativo de la ética capitalista y la manifestación del espíritu de los tiempos.

Ciertamente, los contextos económico y cultural sobre los que Max Weber pensó son diferentes a los actuales, pero la descripción es válida en muchos aspectos. El deber del trabajo, la obtención de beneficios, el dinero y las ganancias son motores de la ética en los negocios. De ahí, la concepción del tiempo como algo a resguardar y controlar. En el capitalismo líquido ${ }^{70}$ del conocimiento, las operaciones fundamentales están organizadas en forma de redes y se basan en el procesamiento de la información ${ }^{71}$. Tomando conjuntamente tres de los elementos claves: i) el cambio en la estructura de la empresa, ii) el cambio en la estructura del mercado laboral y, iii) el papel que desempeña la innovación en el crecimiento económico y en el desarrollo de las sociedades, podemos aproximarnos a la reconsideración de la ética del trabajo para estos tiempos. El elemento repetido es la pasión creativa. ¿Sobre qué principios se asienta?, en la interiorización de que la creatividad es el bien a proteger y en el desarrollo abierto y compartido de ideas. La conclusión es que las ideas novedosas y creativas son el motor de la cultura, de tal suerte que los dos elementos principales de la relación con el trabajo -tal y como explica Himanen- son: 1) la pasión creativa y 2) la relación flexible con el tiempo.

La extensión de este tipo de ética y del paradigma cultural adscrito, no es factible en todas las formas de trabajo. La paradoja es clara, se cantan las excelencias de la innovación, la capacidad de crear creatividad y del poder de autotransformación, pero hay un contingente de personal laboral que no llega al estadio requerido para participar plenamente de esos bienes. Muchos empleos consisten en la ejecución de rutinas y en la reiteración de tareas y dejan poco espacio a la capacidad creativa. En ese tipo de escenarios, la ética puritana tradicional tiene sentido; el trabajo es una obligación no creativa. Sin embargo, en cada vez más empleos la ética protestante no sólo no tiene sentido, es contraproducente ${ }^{72}$. Cuando el éxito de la empresa depende de los requisitos de la innovación es necesaria una cultura laboral distinta. Por eso, las nuevas empresas -0 la literatura de autoayuda- ${ }^{73}$ se empeñan en cargar la mano sobre ideas como las de creatividad, o el valor de los riesgos asumidos. La estructura jerárquica ${ }^{74}$ sitúa en la cúspide de la sociedad del conocimiento a un conjunto de grupos sociales. Están formados por elites cuyo poder, especialmente en las ciudades globales de Europa y América del Norte ${ }^{75}$, ha crecido. En todos los casos se orientan hacia el valor que adquiere una forma distinta de comprender lo que es la estructura social de la sociedad del conocimiento.

La paradoja es que, por lo general, las divisiones de clase en la sociedad del conocimiento pasan a estar determinadas por las diferencias de oportunidades vitales ${ }^{76}$. Ésta es una transformación significativa. En realidad ante eso se abren un abanico de nuevas inseguridades. La mayoría de las personas esperan de sus vidas más que generaciones anteriores, lo cual conduce a tener aspiraciones y expectativas que no siempre pueden realizarse. La democratización de las expectativas se reparten entre los grupos sociales, de tal forma que lo que distingue unos de los otros es el acceso a las oportunidades que permiten acceder a las mismas. La estructura de la sociedad de la innovación apunta al proceso de diversificación donde los estilos de vida y los conflictos culturales ocupan el lugar central, pero la materialización de nuevas divisiones sociales no beben de los códigos culturales de clase sino de los estilos de vida asociados al empleo concreto del que disfrutan y al cuadro de expectativas, posibilidades y oportunidades reales. De tal suerte, que mientras las expectativas se democratizan y traspasan fronteras o divisiones sociales, las oportunidades están sujetas y limitadas por el tipo y el carácter de empleo que se desarrolla ${ }^{77}$.

Los trabajadores del conocimiento auto programados tienen un estatus de vida y acceso a sus expectativas vitales 
de las que no disfrutan los trabajadores genéricos ${ }^{78}$, reemplazables, que se mueven en el magma que en la sociedad del conocimiento es el sector servicios, que disfrutan del derecho democrático a soñar y a participar en la sociedad de las expectativas, por más que sus condiciones objetivas de vida le niegan las oportunidades que se anuncian en casi todos los canales, formales o informales, de comunicación. Una de las consecuencias de todo esto es que la sociedad de la innovación faculta que se realicen los sueños de unos, pero no permite el acceso a ellos de otros. La consecuencia es que entre la democratización de las expectativas y las oportunidades reales se producen falta de sintonía.

El peligro y origen de las paradojas es que la estructura social de la innovación termine soportada por minorias de individuos que prestan sus servicios en puestos de trabajo dependientes de la creación y la gestión del conocimiento, mientras que el sector mayoritario -desperdigado en el mundo fragmentado del sector servicios- no juega este juego porque las posibilidades les indican otros caminos y lugares. En este caso, no es infrecuente encontrarse con que el discurso de la innovación es la retórica de sectores sociales que ocupan posiciones de elite en la estructura social de la sociedad del conocimiento, que disponen de recursos culturales y de oportunidades para realizar el "sueño" de la innovación, pero el cuadro de oportunidades no corre por el interior de la red hacia otros sectores que ocupan posiciones sociales subordinadas. Por ejemplo, la sociedad de bajo coste -ryanair society- ${ }^{79}$ ilumina el corte social y disemina la paradoja constitutiva de la sociedad del conocimiento, es decir, la sociedad instala la idea del acceso en su caja de herramientas, pero no genera suficientes oportunidades para que las expectativas se realicen. Este hecho es importante si analizamos la caja de herramientas con la que opera la sociedad de la innovación, o cuando bajo este epígrafe no son acogidos los trabajadores genéricos, los trabajadores del sector servicios -reemplazables-, mileuristas o premileuristas, con pocas posibilidades de abandonar su trabajo para irse a otros de los que promete la sociedad de las expectativas ${ }^{80}$.

Me he referido a lo largo del texto a la hipótesis de que innovación e incertidumbre caminan en paralelo, de tal suerte que cuando se incrementa el grado de incertidumbre se hacen necesarios los recursos y las llamadas a la innovación. Por eso es difícil sostener, por ejemplo, defi- niciones esenciales de casi nada, quizá porque, como nos enseñó C. Geertz, al profundizar en los detalles de estos temas, desde cualquier caso particular, se descubre que las demarcaciones más obvias se hallan desbordadas por otras demarcaciones más finas y distinguibles con mayor exactitud y sutileza, y otras más gruesas, amplias y generales.

\subsection{La Innovación y la teoría del cambio}

El análisis de la innovación genera, como he puesto de manifiesto, un cuarto tipo de paradojas. El reconocimiento explícito de la innovación, aunque polémico ${ }^{81}$, es reciente y se ha desarrollado sobre todo, originalmente desde el ámbito de la economía. ¿Pero, por qué reconocerse en Schumpeter y el concepto de "destrucción creativa" y no en Weber y en la idea de la personalidad histórica o en su análisis de la racionalización, en Durkheim y el análisis de la diferenciación o en Simmel y el tratamiento de la cultura objetiva o en Marx y el análisis de los procesos de construcción económica del tiempo moderno?

Quizá es conveniente recuperar la teoría del cambio y ver a la innovación como una de sus fuentes y uno de sus procesos. ¿Quién es "el perro guardián" de la innovación, sino el cambio? El peligro que se corre, si olvidamos la teoría del cambio, no sólo es la confusión por sobre uso que provoca la innovación, sino la invasiva constancia de su presencia o la conversión en un concepto más profético que analítico o empírico. Lo que queda, como sabemos, cuando ignoramos la teoría del cambio, es el regreso a fórmulas de ingeniería económica o tecnología social, cuando lo que el análisis empírico demuestra es la confrontación, la división entre múltiples fuentes y formas de innovación. Otro dato es la insuficiencia de la investigación empírica al respecto. En todo caso, faltan análisis empírico concretos, investigación de casos y situaciones para saber si realmente la innovación es un objeto fiable para comprender aspectos sustanciales del cambio o si no tiene recorrido fuera de la carcasa teórica y analítica que proporcionan estas teorias.

\section{CONCLUSIÓN}

A modo de síntesis, sólo un nuevo lenguaje teórico, una narrativa comprensiva y la clarificación conceptual puede evitar los peligros que detecto, pero es verdad que la 
narrativa de la innovación transita por terrenos de moda "pantanosos", donde no es extraño que pudiese extraviarse porque la retórica y la simulación pueden tener capacidad para disolver la capacidad crítica y explicativa del fenómeno 0 , incluso, transformarlo en un placebo. El discurso, la narrativa de la innovación que acude en auxilio del individuo sin atributos no hace sino darle una carta de navegación, no basada en un rumbo seguro sino en las recetas que pueden funcionar para ese momento, pero no para otros momentos que han de sucederle, pero que no tienen la facultad de situarle en el mundo.

La paradoja es que de la necesidad de poseer un entramado socio-material solvente, más o menos fijo, se transita hacia la caja de herramientas donde la innovación lo que reclama no es un fin u objetivo que pueda ser terminado, sino la carta de navegación cuyos hitos no están definidos del todo y donde se llama a valores, actitudes y a un estado de ánimo. El problema, mucho me temo, no es de expectativas, es de oportunidades. ¿Dónde están y quién las tiene?

Mi tesis es que la disolución de los condicionamientos socio-materiales, tal y como se presentan en la literatura económica y organizativa sobre innovación, las actitudes flexibles o la mentalidad de consumidor, no son elementos suficientemente sólidos. La cuestión abierta, y que está por resolver, es si las llamadas a la innovación social no se corresponden con los requisitos que debiera tener para no tener que enfrentarse al problema de fondo; la licuación ${ }^{82}$ de la solvencia social y la imposibilidad de hacer viables las expectativas generadas en las situaciones contemporáneas con las oportunidades creadas en este tiempo histórico. Mientras eso ocurre, la crítica política a la retórica de la innovación la percibe como el placebo que quiere aunar lo que se cree que es encomiable, pero difícil de conjugar con los requisitos que necesitamos para llevar a cabo las metas propuestas $^{83}$. No sabemos si las explicaciones alrededor de qué es la innovación social conseguirá abandonar la jaula de la sociedad líquida ${ }^{84}$. La llamada a aceptar las reglas del cambio, la interiorización del valor social del riesgo, la lógica abierta de las oportunidades, los caminos de la flexibilidad o las llamadas a la solvencia de la mutación no parecen suficientes argumentos para encontrar el oasis que se busca, cuando sabemos que en él los espejismos forman parte de la caja de herramientas y del equipaje con el que uno se lanza a esta aventura. Si así fuese innovar se transforma no en una nueva lógica social, capaz de transformar ese estado de cosas, sino en el placebo que permite soportar "la que está cayendo".

\section{NOTAS}

1 X. Ferrás, Innovación 6.0, Plataforma Editorial, Barcelona, 2010, p. 20.

2 P. Drucker, La Innovación y el Empresariado Innovador, Apóstrofe, BarceIona, 1986, p. 87.

3 M. E. Porter, The Competitive Advantage of Nations, The Macmillan Press, London y Basingstoke, 1990.

4 La historia, sobre todo, los historiadores que se ocupan de largos ciclos nos han descubierto el valor de la innovación a lo largo del timpo de las civilizaciones. Ver, por ejemplo los textos de D. Christian, Mapas del Tiempo, Crítica, Barcelona, 2005. R. Robertson, 3 Olas de Globalización, Alianza, Madrid, 2005. J. R. McNeill y W. H. McNeill, Las Redes Humanas, Crítica, Barcelona, 2004. P. Jay, La Riqueza de las Naciones, Crítica, Barcelona, 2002. Es muy recomendable J. Diamond, Armas, Gérmenes y Acero, Debate, Madrid, 1998.

$5 \mathrm{El}$ análisis de M. Castells al respecto en La Era de la Información. La Sociedad Red, Vol. I, Alianza, Madrid, 1997, sigue siendo ejemplar.

6 Manual de Frascatti, 6. ${ }^{a}$ edición, FECYT, 2002.

7 Manual de Oslo, OECD/European Communities, 2005.

8 Manual de Bogotá, RICYT/OEA/CYTED, 2001.

9 El texto de P. Drucker, titulado "La Empresa en la Sociedad que viene", Empresa Activa/Nuevos Paradigmas,
Recibido: 23 de junio de 2010

Aceptado: 20 de octubre de 2010

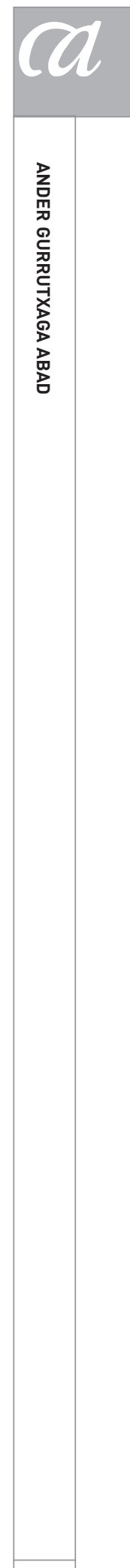

1057 
Ediciones Urano, Madrid, 2003, sigue siendo un buen análisis de la relación entre contextos empresariales y cambio social. Una magnífica introducción al tema es el artículo de Luis E. Alonso y Carlos Fernández, titulado "El Imaginario 'managerial': el discurso de la fluidez en la sociedad económica", Política y Sociedad, n. 43 (2), pp. 127-151.

10 E. Illouz, La Salvación del alma moderna, Katz, Buenos Aires, 2010. Intimidades Congeladas, Katz, Buenos Aires, 2007.

11 El texto, ya citado, de X. Ferrás, Innovación 6.0, p. 25 interpreta, quizá con un tono agónico, este mar de problemas. Dice así, "La innovación trascenderá la lógica económica y se convertirá en un auténtico modo de vida. La innovación será en definitiva, el instrumento que nos permitirá fluir en un contexto de absoluta incerteza, adoptándolo como principio vital".

12 La propuesta interpretativa de Z. Bauman, en Modernidad Líquida, FCE, México, 2003, es un foco de contaminación ideática que penetra casi en el subsuelo de la cultura organizativa de la empresa.

13 M. Castells lo describía muy bien cuando en La Era de la Información. La Sociedad Red, Vol. I, p. 108, decía: "la rentabilidad y la competitividad son los determinantes reales de la innovación tecnológica y el crecimiento de la productividad. Es en su dinámica histórica y concreta donde podemos encontrar las pistas para comprender los caprichos de la productividad".

14 Los textos citados de E. Illouz, Intimidades Congeladas, op. cit. y La Salvación del Alma moderna, op. cit., son un análisis de la importancia de los valores en las organizaciones, cómo construirlos y cómo se incorporan al mundo de las instituciones. Hay que seguir los textos de S. Lash, ambos muy lúcidos; El primero escrito con J. Urry, titulado, Economías de Signos y Espacios, Ed. Amorrortu, Buenos Aires, 1998. S. Lash, Crítica de la Información, Amorrortu, Buenos Aires, 2005. No puedo dejar de citar los textos de L. Boltanski y E. ChiapeIlo, El Nuevo Espíritu del Capitalismo, Akal, Madrid, 2002 y el magnífico análisis de R. Sennett, titulado, La Cultura del Nuevo capitalismo, Anagrama, Barcelona, 2006.

15 J. A. Schumpeter, Capitalismo, Socialismo y Democracia, Folio, Barcelona, 1984. Hay una reciente versión abreviada, con tres magníficas presentaciones y un epílogo de $\mathrm{H}$. Reinert y $E$. Reinert donde reivindican las figuras de F. Nietzsche y W. Sombart como antecedentes necesarios $y$ básicos del pensamiento de Schumpeter, titulada, ¿Puede sobrevivir el capitalismo? La destrucción creativa y el futuro de la economía global, Capitan Swing Libros, Madrid, 2010.

16 P. Drucker, La Innovación y el Empresariado Innovador, op. cit., pp. 235330.

17 Los textos de E. Illouz, Intimidades Congeladas, Katz, Buenos Aires, 2007 y La Salvación del alma moderna, Katz, Buenos Aires, 2010, resumen muy bien este debate y la forma cómo la ayuda mutua, la personalidad y la comunicación se transforman en la planta teórica de la comprensión del ser creativo o emprendedor.

18 Son muy instructivos al respecto las tesis de M. Castells, en La Era de la Información, sobre todo, en el vol. I, La Sociedad Red, op. cit., especialmente las pp. 31-357.

19 Las tesis de S. Lash, son muy interesantes. En su libro Crítica de la In- formación, Amorrortu, Buenos Aires, 2005, pp. 37-58.

20 El libro clásico de Amitai Etzioni y Eva Etzioni, Los Cambios Sociales, FCE, México, 1968, sintetiza muy bien las diversas corrientes y analiza la innovación como un proceso del cambio, pp. 380-382.

21 R. K. Merton, Teoría y Estructura Sociales, FCE, 3. a edición, 1992, pp. 220228.

22 P. Sztompka, Sociología del Cambio Social, Alianza, Madrid, 1995, la innovación es analizada desde el capítulo dedicado (pp. 261-275) a las ideas como fuerzas históricas, a partir del legado weberiano y de las teorias de la personalidad innovadora. En otro capítulo posterior, el surgimiento de lo normativo: evasiones e innovaciones (pp. 277-286) la innovación se analiza desde la asunción y legitimación de los cambios normativos, ni que decir que los capítulos dedicados a los movimientos sociales como fuerzas de cambio o en el apartado dedicado a las revoluciones, la innovación está presente, pero siempre asociada a los cambios que evita o provoca.

23 Hay una auténtica avalancha de títulos y autores fundamentales para comprender esta posición. Pese al tiempo transcurrido me sigue pareciendo de gran valor el texto introductorio a esta polémica de B. A. Lundvall, titulado, "La Base del conocimiento y su producción", Ekonomiaz, n. ${ }^{0} 45$, 1999, pp. 14-37, o el de Susana Borrás, "La política de la innovación en la economía del aprendizaje", Ekonomiaz, n. 45, 1999, pp. 142-159. Por supuesto los clásicos de esta corriente, siguen siendo, el texto de B. A. Lundvall (ed.), National Systems of Innovation: Towards a Theory of Innovation and Interactive 
Lerning, Pinter Publishers, London, 1992. C. Freeman, Technology policy and economic perfomance. Lessons from Japan, Pinter Publishers, London, 1987. I. Nonaka y H. Takeuchi, The Knowledge Creating Company, Oxford University Press, Oxford, 1995. Me parece también muy interesante la obra de Carlota Pérez. Por resumir en un texto sus aportaciones, podría citar a, Revoluciones tecnológicas y Capital Financiero, Ed. Siglo XXI, México-Buenos Aires, 2004. Es también muy sugerente el libro colectivo, editado por C. Cañibano, M. I. Encinar y F. F. Muñoz (coords.), Economía del Conocimiento y la Innovación. Nuevas aproximaciones a una relación compleja, Pirámide, Madrid, 2008

24 Me parecen de gran valor los textos de S. Lash y J. Urry, The End of Organized Capitalism, Cambridge Polity Press, 1987 y el ya citado, Economías de Signos y Espacios, Amorrortu, Buenos Aires, 1998.

25 Los textos de S. Sassen, Los Espectros de la Globalización, FCE, Buenos Aires, 2003 y Una Sociología de la Globalización, Katz, Buenos Aires, 2007, son magníficos exponentes de las consecuencias del "éxito".

26 Ver S. Sassen, Una Sociología de la Globalización, Katz, Buenos Aires, 2007, pp. 125-164.

27 Ver los textos de J. Echeverria. "Modelo pluralista de innovación: el ejemplo de las Humanidades", en A. Ibarra, J. Castro y L. Rocca (eds.), Las ciencias sociales y las humanidades en los sistemas de innovación Estudios de Ciencia, Tecnología e Innovación, 2, UPV/EHU, Cátedra Sánchez-Mazas, 2006, pp. 135-155. "El Manual de Oslo y la innovación social", Arbor, 732, 2008, pp. 609618. "Aportaciones preliminares a los estudios de innovación social", en I. Mendiola (ed.), Textos y Pretextos para repensar lo social, Bilbao, Universidad del País Vasco, 2008, pp. 81-96. "Giro social en los estudios de innovación: el ejemplo del Reino Unido", Inguruak, Revista Vasca de Sociología y Ciencia Política, Actas del VIII Congreso Vasco de Sociología y Ciencia Política, "Sociedad e Innovación en el Siglo XXI", Bilbao, CD-Rom, Grupo 20, 2010, pp. 56-67. "De las políticas de investigación a las políticas de innovación", Acta Sociológica (México), 55:1, 2010, pp. 13-37.

28 Los textos de E. Von Hippel (1988), The sources of innovation, New York, Oxford Univ. Press, 1998. Democratizing Innovation, Cambridge, MA, MIT Press, 2005, son muy ilustrativos a este respecto.

29 Los textos de J. Gray, Falso Amanecer, Paidós, Barcelona, 2000; Las dos Caras del Liberalismo, Paidós, Barcelona, 2001, son dos aportaciones interesantes al territorio de las dificultades para la penetración de esta pragmática.

30 El texto de R. Sennett, La Corrosión del Carácter, Anagrama, Barcelona, 2000, es un análisis espléndido de esta compleja y difícil relación. EI ya citado análisis de L. Boltanski y W. Chiapello, El Nuevo Espíritu del Capitalismo, Akal, Madrid, 2002, es un texto clave para entender las dificultades de la relación.

31 Los textos de L. E. Alonso, La crisis de la ciudadanía laboral, Barcelona, Anthropos, 2007, y L. E. Alonso y C. Fernández Rodríguez, "El imaginario 'managerial': el discurso de la fluidez en la sociedad económica", Política y Sociedad, 43 (2), 2006, pp. 127-151, son dos magníficas aproximaciones a ese marco de problemas.
32 Me parecen muy instructivas las lecturas de los textos del historiador D. Christian, Mapas del Tiempo, Crítica, Barcelona, 2005 y la de J. R. McNeill y W. McNeill, Las Redes Humanas, Crítica, Barcelona, 2004. En ellos se traza una aventura histórica donde la innovación tiene un relevante papel.

33 Es muy interesante el breve texto -escrito en 1937- de H. M. Kallen, titulado Innovación, pp. 380-382, que recogen A. Etzioni y E. Etzioni, en su clásico libro, Los Cambios Sociales. Fuentes, tipos y consecuencias, FCE, México, 1964.

34 A. André, Ch. Loos y L. Pirez, Building an innovation nation, Mckinsey Company, What Matters, marzo, 2009 (http//whatmatters,mckinseydigital. com).

35 Comisión Europea. Informe de J. M. Barroso, Prioridades de Europa en materia de innovación, febrero, 2001.

36 El artículo de J. Echeverria, en este mismo número de Arbor, titulado "Cambio de Paradigma en los estudios de Innovación. El giro social de las políticas europeas de innovación", es un magnífico análisis de la historia y los vaivenes de la innovación social desde los discursos y la praxis de las instituciones europeas.

37 Los textos ya citados, de C. Feeman, B. A. Lundval, C. Pérez o los análisis de economistas como P. Cooke/Mémedovic, Strategies for Regional Innovations Systems: Learning Transfer and Applications, Unido Polycy Papers, Viena, 2003; Regional Innovation Systems as public Goods, UNIDO, Viena, 2006. Es muy interesante y sintético el n. 70 de la revista Ekonomiaz, dedicada al análisis de los Sistemas Regionales de Innovación, 2009, son una muestra de un campo muy productivo. 
38 Algunos de los autores más sugerentes son: D. Apter, Some conceptual Approaches to the self of modernization, Englewood Cliffs, Prentice Hall, 1968. D. Bell, El advenimiento de la sociedad postindustrial, Alianza, Madrid, 1991; S. Eisenstadt, Modernization, protest and change, Englewood Cliffs, Prentice Hall, 1966; Traditin, change and modernity, Wiley, Nueva York, 1973-1968. W. Moore, Social change, Englewood, Prentice Hall, 1963; J. P. Nettl. y R. Robertson, International systems and the modernization of societies, Faber and Farber, Londres, 1968; R. Nisbet, Cambio social Alianza, Madrid, 1993; T. Parsons, The System of modern societies, Englewood Cliffs, Prentice Hall, 1971; W. Rostow, Las etapas del crecimiento económico, Ministerio de Trabajo, Madrid, 1993; N. Smelser, Theory of collective behavior, Free Press, Nueva York, 1962; P. Stzompka, Sociología del cambio social, Ed. Alianza, Madrid, 1995.

39 Una magnífica mirada a algunos de estos nuevos dilemas es el texto, ya citado, de S. Sassen, Sociología de la Globalización, Katz, Buenos Aires, 2007.

40 Para marcar bien estos pasos son muy sugerentes las ideas de R. Heilbroner, Visiones del Futuro, Paidós, Barcelona, 1996.

41 M. Castells, P. Himanen, Pekka, "Modelos Institucionales de Sociedad Red: Silicon Valley Finlandia", en Castells, M. (Ed.), La Sociedad Red: una Visión Global, Alianza, Madrid, 2006, pp. 79-119. Ch. Edquist y L. Hommen, Small Country Innovation Systems: Globalization, Change and Policy in Asia and Europe, 2008. Timo Hamalainen y R. Heiskala (Eds.), Social Innovations, Institutional Change and Economic Performance: Making
Sense of Structrual Adjustment Processes in Industrial Sectors, Regions and Societies, SITRA, 2007, Edward Elgar, Chentelham. Saxenian, Anna Lee, Regional Advantage. Culture and Competition in Silicon Valley and Route 128, Harvard University Press, 1997; Anna Lee Saxanian, The New Argonauts. Regional Advantage in a Global Economy, Harvard University Press, 2007; Van Den Berg, Leo, P. M. Pol, W. Van Winden y P. Woets, European Cities in the Knowledge Economy, Aldershot, Ashgate, 2005.

42 La categoría de E. Goofman, ver La Presentación de la Persona en la vida cotidiana, Amorrotu, Buenos Aires, 1968 y Frame Analysis, CIS, Madrid, 2004, nos introducen, aunque con una perspectiva micro en este ambiente de discusión.

43 Saxenian, Anna Lee, The New Argonauts: Regional Advantage in a Global Economy, Cambridge, Harvard University Press, 2007. Scott, Allen J., Regions and the World Economy: the Coming Shape of Global Production, Competition and Political Order, Oxford, Oxford University Press, 1998; Global City-Regions: Trends, Theory, Policy, Oxford, Oxford University Press, 2001. Lee, Moon; MiIler, William F.; Hancock, Marguerite G. y Rowen, Henry S. (eds.) (2000), The Silicon Valley Edge: a Habitat for Innovation and Entrepreneurship, Stanford, Stanford University Press.

44 Ver el texto de M. Castells y P. Himanen en La Sociedad Red, Alianza, Madrid, 2006.

45 A. Chowdury y I. Islam, The Newly Industrialising Economies of East Asia, London, Routledge, 1993. P. J. Katzenstein, "East Asia - Beyond Japan", en P. J. Katzenstein y T. Shiraishi (eds.), Beyond Japan: the Dynamics of East Asian Regionalism, New
York, Cornell University Press 2006, pp. 1-35.

46 S. Sassen, Los Espectros de la Globalización, FCE, Buenos Aires, 2003. Una Sociología de la Globalización, Katz, Buenos Aires, 2007. La Ciudad Global, FCE, Buenos Aires, 1999.

47 0. Crevoisier y R. Camagni (eds.), Les milieux urbains: innovation systemes de production et ancrage, Neuchatel, EDES, 2000; OCDE, Knowledge Economy; OCDE, Paris, 1996. Cities and Regions in the New Lerning Economy, Paris, 2006. N. Kominos, Intelligent Cities: Innovation Knowledge Systems and Digital Spaces, Londres, 2002. W. Winden, L. Van der Berg y P. Pol, "European Cities in the Knowlwdge Economy: Towards a Typology", Urban Studies, vol. 44, n. 3 , 2007. P. Hall, "Creative Cities and Economic Development", Urban Studies, vol. 37, n. ${ }^{\circ}$, 2000. R. Florida, The Rise of the Creative Class: and how it's transforming work, leisure, community, and everyday life, Basic Books, Nueva York, 2002. The flight of the creative class: the new global competition for talent, Harper Bussines, Nueva York, 2005. A. Jones, L. WiIliam, N. Lee, N. Coats y M. Cowling, Ideopolis: Know/wdge City-Regions, Bristol University, 2006.

48 A. Soja, Postmetrópolis, Madrid, 2008.

49 F. Ascher, Los Nuevos principios del Urbanismo, Alianza, Madrid, 2004.

50 S. Sassen, Una Sociología de la Globalización, Katz, Buenos Aires, 2007, p. 139

51 F. Ascher, Los Nuevos principios del Urbanismo, op. cit., pp. 71-86.

52 S. Lash, Crítica de la Información, op. cit., p. 42.

53 Este concepto es clave en la orientación de M. Castells, La Era de la Información. La Sociedad Red, op. cit. 
54 S. Lash, Crítica de la Información, op. cit., pp. 59-78, su aportación de la zonificación espacio-identitaria de las ciudades parece una muy sugerente aportación.

55 Las tesis están contenidas en la obra, ya citada, de M. Castells, La Ciudad Informacional, op. cit., pp. 189-247.

56 R. Reich, El trabajo de las naciones. Hacia el capitalismo del siglo $X X I$, Vergara Editores, Buenos Aires, 1993.

57 Es una de las tesis, aunque ya había aparecido en otros trabajos, de M. Castells, Comunicación y Política, Alianza, Madrid, 2009.

58 Las tesis de R. Florida, especialmente las recogidas en dos de sus obras. R. Florida, La Clase Creativa, Paidós Empresa, Barcelona, 2010 y del mismo autor, Las Ciudades Creativas, Paidós Empresa, Barcelona, 2009, inciden este tipo de argumentos.

59 W. Winden, L. Van der Berg y P. Pol, "European Cities in the Knowlwdge Economy: Towards a Typology", Urban Studies, vol. 44, n. 3 3, 2007.

60 Ver los textos, ya citados, de R. Robertson, Las Tres Olas de la Globalización. Alianza, Madrid, 2004; de D. S. Landes, La Pobreza y la Riqueza de las Naciones, Crítica, Barcelona, 2002; de D. Christian, Mapas del Tiempo, Crítica, Barcelona, 2006; J. R. y W. MacNeill, Las Redes Humanas, Crítica, Barcelona, 2007; R. Osborne, Civilización, Crítica, Barcelona, 2008, son una muestra valiosa de cómo cambia la perspectiva cuando se mira la construcción de la era global con una gran perspectiva histórica.

61 Son muy atractivas, todavía hoy más si cabe, la obra de J. Baudrillard, Cultura y Simulacro, Kairós, Barcelona, 1978.
62 El texto del gurú de la innovación empresarial, T. Kelley refleja la cara abierta, poliédrica y abarcante de la praxis innovadora y de los innovadores que se "atreven" con ella. Ver su libro T. Kelley y J. Littman, Las Diez Caras de la Innovación, Paidós Empresa, Barcelona, 2010.

63 Hay que volver a mirar textos como los tres volúmenes, ya citados de M. Castells, La Era de la Información, Alianza, Madrid, 1997/1998. Otro texto anterior como es La Ciudad Informacional, Alianza, Madrid, 1995. El libro que escribe junto con P. Himanen, El estado del bienestar y la sociedad de la información, Alianza, Madrid, 2002, o los textos ya citados de S. Lash, Crítica de la Información, op. cit., o el que escribe junto a J. Urry, Economías de Signos y Espacios, op. cit. o el libro-informe de A. Giddens, titulado Informe Social de Europa, Paidós, Barcelona, 2008, o los textos citados de S. Sassen, Una Sociología de la Globalización, op. cit., que ponen mucho énfasis en los cambios provocados en la estructura social y en los contextos laborales para intentar comprender en toda su dimensión este aspecto.

64 La distinción es de M. Castells, en vol. III de La Era de la Información. Fin de Milenio, es muy sugerente, op. cit., pp. 374-385.

65 Ver, por ejemplo, y lo cito porque me parece ejemplar su propuesta el texto de X. Ferrás, Innovación 6.0, op. cit. Este autor señala, pp. 19-26, lo siguiente, "la innovación es un campo emergente de Management". Un campo que integra conceptos de estrategia, marketing, tecnología, teoría organizativa e iniciativa emprendedora. Y, a la vez, que los engloba en un todo coherente, los supera a todos ellos, generando un nuevo enfoque integral de la empresa.

66 Textos muy interesantes al respecto son los de Dani Rodrik, Has globalization gone too far?, Institute for International Economics, Washington, 1997. The global governance of trade as if development really mattered, en www.undp. org/bdp. Free trade optimism, Foreign Affairs, mayo-junio, 2003.

67 D. Bell, Las Contradicciones Culturales del Capitalismo, Alianza, Madrid, 1978.

68 Max Weber, La Ética puritana y el espíritu del Capitalismo, Península, Barcelona, 1969 (1. ${ }^{\text {a edición). }}$

69 A. O. Hirschman, Las Pasiones y los intereses, Península, Barcelona, 1999, es un texto clarificador donde se analiza la construcción de los intereses culturales que hacen posible el capitalismo.

70 Z. Bauman, Modernidad Líquida, FCE, México, 2002.

71 M. Castells, La Era de la Información, vol. I, op. cit., pp. 27-53.

72 Aquí el análisis de Z. Bauman vuelve a ser intrigante. Ver, por ejemplo, La Posmodernidad y sus descontentos, op. cit., o el capítulo que dedica al trabajo en La Modernidad Líquida pp. 139-178. El texto de R. Sennett, La Corrosión del Carácter, op. cit., no deja lugar a dudas sobre el carácter comprometido de la creatividad laboral. Para completar este recorrido debemos acercarnos al texto, ya citado, de L. Boltanski y E. Chiapello, El Nuevo Espíritu del Capitalismo, Akal, Madrid, 2002.

73 E. Illouz, Intimidades Congeladas, op. cit.; La salvación del alma moderna op. cit.

74 R. Florida, La Clase Creativa, Paidós Empresa, Barcelona, 2010.

75 R. Florida, Las Ciudades Creativas, op. cit.; S. Sassen, Espectros de Globali- 
zación, op. cit.; Una Sociología de la Globalización, op. cit.

76 A. Giddens, "El debate sobre el modelo social", en Un modelo social para Europa, PUV, Valencia, 2008, pp. 114-171.

77 Ver, entre otros, Z. Bauman, La Sociedad Sitiada, FCE, México, 2004.

A. Giddens, Informe Social Europeo, Paidós, Barcelona, 2008. M. Castells, La Era de la Información, vol. III, op. cit. U. Beck y E. Grande, La Europa Cosmopolita, Paidós, Barcelona, 2006. U. Beck, La Sociedad del Riesgo mundial, Paidós, Barcelona, 2008.

78 Ésta es la forma como M. Castells, La Era de la Información, vol. III, pp. 374-385, define la situación objetiva de los trabajadores en la sociedad informacional.

79 Los conceptos están descritos en los textos de M. Giggi y E. Narduzzi, El fin de la clase media, Lengua de Trapo, Madrid, 2006, p. 9, y Pleno Desempleo, Lengua de Trapo, Madrid, 2008, que es una prolongación de los argumentos del primero. Sus tesis son provocativas y más retóricas que argumentadas empíricamente pero, en todo caso, muy sugestivas.

80 Este es un concepto de G. Sartori, que desarrolla en su libro, La democracia después del comunismo, Alianza, Madrid, 1993, pp. 118-123.

81 La discusión de la tesis de J. Schumpeter por parte de Hugo y Erik Reinert es muy interesante, al recuperar para ello las tesis de F. Nietzsche y W. Sombart. Ver H. Reinert, "La destrucción creativa en Economía: Nietzsche, Sombart, Schumpeter", en ¿Puede sobrevir el capitalismo?, Capitán Swing, Madrid, 2011, pp. 237-278.

82 Ver Z. Bauman, Modernidad Líquida, op. cit., pp. 99-138.
83 Los capítulos de Z. Bauman, en Modernidad líquida, op. cit., dedicados al análisis de la Individualidad, pp. 5998 y el Espacio/Tiempo, pp. 99-138 son muy sugerentes para el problema que discutimos.

84 Bauman, Z., Modernidad Líquida. op. cit.

\section{BIBLIOGRAFÍA}

Allen, J. (2001): Global City-Regions: Trends, Theory, Policy, Oxford, Oxford University Press.

Allen, J. (1998): Regions and the World Economy: the Coming Shape of Global Production, Competition and Political Order, Oxford, Oxford University Press.

Alonso, L. E. (2007): La crisis de la ciudadanía laboral, Anthropos, BarceIona.

Alonso Luis, E. y Carlos Fernández, "El Imaginario 'managerial': el discurso de la fluidez en la sociedad económica", Politica y Sociedad, n. ${ }^{\circ} 43$ (2).

Amitai Etzioni y Eva Etzioni (1968): Los Cambios Sociales, FCE, México.

André, A.; Ch. Loos y L. Pirez (2009): Building an innovation nation, Mckinsey Company, What Matters (http://whatmatters.mckinseydigital.com).

Apter, D. (1968): Some conceptual Approaches to the self of modernization, Englewood Cliffs, Prentice Hall.

Ascher, F. (2004): Los Nuevos principios del Urbanismo, Alianza, Madrid.

Barroso, J. M. (2011): Prioridades de Europa en materia de innovación, Comisión Europea, Bruselas.

Baudrillard, J. (1978): Cultura y Simulacro, Kairós, Barcelona.

Bauman, Z. (2004): La Sociedad Sitiada, FCE, México.

Bauman, Z. (2002): Modernidad Líquida, FCE, México.
Bauman, Z. (2001): La Posmodernidad y sus Descontentos, Akal, Madrid.

Beck, U. y Grande, E. (2006): La Europa Cosmopolita, Paidós, Barcelona.

Beck, U. (2008): La Sociedad del Riesgo mundial, Paidós, Barcelona.

Bell, D. (1978): Las Contradicciones Culturales del Capitalismo, Alianza, Madrid.

Bell, D. (1991): El advenimiento de la sociedad postindustrial, Alianza, Madrid.

Boltanski, L. y W. Chiapello (2002): El Nuevo Espíritu del Capitalismo, Akal, Madrid.

Borrás, S. (1999): "La política de la innovación en la economía del aprendizaje", Ekonomiaz, n. 45.

Cañibano, C.; Encinar, M. I. y Muñoz, F. F. (coords.) (2008): Economía del Conocimiento y la Innovación. Nuevas aproximaciones a una relación compleja, Pirámide, Madrid.

Castells, M. (1995): La Ciudad informacional, Alianza, Madrid.

Castells, M. (1997-1998): La Era de la Información, Alianza, Madrid.

Castells, M. (2009): Comunicación y Política, Alianza, Madrid.

Castells, M. y Himanen, P. (2002): El Estado del bienestar y la sociedad de la información. El modelo finlandés, Alianza, Madrid.

Castells, M. y Himanen, P. (2006): "Modelos Institucionales de Sociedad Red: Silicon Valley Finlandia" (Ed.), La Sociedad Red: una Visión Global, Alianza, Madrid.

Chowdury, A. e Islam, I. (1993): The Newly Industrialising Economies of East Asia, London, Routledge.

Christian, D. (2005): Mapas del Tiempo, Crítica, Barcelona.

Cooke, P. y Mémedovic (2003): Strategies for Regional Innovations Systems: Learning Transfer and Applications, Policy Papers, Viena. 
Cooke, P. y Mémedovic (2006): Regional Innovation Systems as public goods, UNIDO, Viena.

Crevoisier, O. y Camagni, R. (eds.) (1996): Knowledge Economy, OCDE, París.

Crevoisier, 0. y Camagni, R. (eds.) (2000): Les milieux urbains: innovation systemes de production et ancrage, Neuchatel, EDES.

Crevoisier, 0. y Camagni R. (eds.) (2006): Cities and Regions in the New Lerning Economy, París.

Diamond, J. (1998): Armas, Gérmenes y Acero, Debate, Madrid.

Drucker, P. (1986): La Innovación y el Empresariado Innovador, Apóstrofe, Barcelona.

Drucker, P. (2003): La Empresa en la Sociedad que viene, Empresa Activa/Nuevos Paradigmas, Ediciones Urano, Madrid.

Echeverria, J. (2006): "Modelo pluralista de innovación: el ejemplo de las Humanidades", en Ibarra, J. Castro y L. Rocca (eds.), Las ciencias sociales y las humanidades en los sistemas de innovación, Estudios de Ciencia, Tecnología e Innovación, Universidad País Vasco, Leioa.

Echeverria, J. y Mendiola, I. (ed.) (2008): Textos y Pretextos para repensar 10 social, Bilbao, Universidad del País Vasco.

Echeverria, J. (2008): Giro social en los estudios de innovación: el ejemplo del Reino Unido, Inguruak, Actas del VIII Congreso Vasco de Sociología y Ciencia Política, "Sociedad e Innovación en el Siglo XXI", Bilbao.

Echeverria, J. (2010): "De las políticas de investigación a las políticas de innovación", Acta Sociológica, México.

Echeverria, J. (2011): "Cambio de Paradigma en los estudios de Innovación. El giro social de las políticas europeas de innovación", Arbor, en edición.

Eisenstadt, S. (1966): Modernization, protest and change, Englewood
Cliffs: Prentice Hall, Traditin, change and modernity, Wiley, Nueva York, 1973.

Elgar, E.; Chentelham y Saxenian, Anna Lee (1997): Regional Advantage. Culture and Competition in Silicon Valley and Route 128, Harvard University Press.

Ferrás, X. (2010): Innovación 6.0, Plataforma Editorial, Barcelona.

Florida, R. (2009), Las Ciudades Creativas, Paidós Empresa, Barcelona.

Florida, R. (2010): La Clase Creativa, Paidós Empresa, Barcelona.

Freeman, C. (1987): Technology policy and economic perfomance. Lessons from Japan, Pinter Publishers, London.

Giddens, A. (2008): Informe Social de Euro$p a$, Paidós, Barcelona.

Giddens, A. (2008): "El debate sobre el modelo social", en Un modelo social para Europa, PUV, Valencia.

Giggi, M. y Narduzzi, E. (2008): Pleno Desempleo, Lengua de Trapo, Madrid.

Giggi, M. y Narduzzi, E. (2006): El fin de la clase media, Lengua de Trapo, Madrid.

Goofman, E. (1968): La Presentación de la Persona en la vida cotidiana, Amorrotu, Buenos Aires.

Goofman, E. (2004): Frame Analysis, CIS, Madrid.

Gray, J. (2000): Falso Amanecer, Paidós, Barcelona.

Gray, J. (2002): Las dos Caras del Liberalismo, Paidós, Barcelona.

Hall, P. (2000): "Creative Cities and Economic Development", Urban Studies, vol. 37, n. $^{\circ} 4$.

Hamalainen, T. y Heiskala, R. (eds.) (2007): Social Innovations, Institutional Change and Economic Performance: Making Sense of Structrual Adjustment Processes in Industrial Sectors, Regions and Societies, SITRA Helsinki.

Heilbroner, R. (1996): Visiones del Futuro, Paidós, Barcelona.
Hirschman, A. O. (1999): Las Pasiones y los intereses, Península, Barcelona.

Illouz, E. (2007): Intimidades Congeladas, Katz, Buenos Aires.

Illouz, E. (2010): La Salvación del alma moderna, Katz, Buenos Aires.

Jay, P. (2002): La Riqueza de las Naciones, Crítica, Barcelona.

Kallen, H. M. (1964): Innovación, en Etzioni y E. Etzioni, Los Cambios Sociales. Fuentes, tipos y consecuencias, FCE, México.

Katzenstein, P. J. y Shiraishi, T. (eds.) (2006): Beyond Japan: the Dynamics of East Asian Regionalism, New York, Cornell University Press.

Kelley, T. y Littman, J. (2010): Las Diez Caras de la Innovación, Paidós, Empresa, Barcelona.

Kominos, N. (2002): Intelligent Cities: Innovation Knowledge Systems and Digital Spaces, Londres.

Landes, D. S. (2002): La Pobreza y la Riqueza de las Naciones, Crítica, Barcelona.

Lash, S. y Urry, J. (1987): The End of Organized Capitalism, Cambridge Polity Press.

Lash, S. y Urry, J. (1998): Economías de Signos y Espacios, Amorrortu, Buenos Aires.

Lash, S. (2005): Crítica de la Información, Amorrortu, Buenos Aires.

Lundvall, B. A. (ed.) (1992): National Systems of Innovation: Towards a Theory of Innovation and Interactive Lerning, Pinter Publishers, London.

Lundvall, B. A. (1999): "La Base del conocimiento y su producción", Ekonomiaz, n. ${ }^{\circ} 45$.

Manual de Bogotá (2001): RICYT/OEA/ CYTED.

Manual de Frascatti (2002): Sexta Edición, FECYT.

Manual de Os/o, (2005): OECD/European Communities.

McNeill, J. R. y McNeill, W. (2004): Las Redes Humanas, Crítica, Barcelona.

Merton, R. K. (1992): Teoría y Estructura Sociales, FCE, 3. ${ }^{\text {a edición. }}$ 
Moon, L.; Miller, W.; Hancock, M.; Rowen, G. y Henry, S. (eds.) (2000): The Silicon Valley Edge: a Habitat for Innovation and Entrepreneurship, Stanford, Stanford University Press.

Moore, W. (1963): Social change, Englewood, Prentice Hall.

Nettl, J. P. y Robertson, R. (1968): International systems and the modernization of societies, Faber and Farber, Londres.

Nisbet, R. (1993): Cambio social, Alianza, Madrid.

Nonaka, I. y Takeuchi, H. (1995): The Knowledge Creating Company, 0xford University Press, Oxford.

Osborne, R. (2008): Civilización, Crítica, Barcelona.

Outhwaite, W. (2008): El futuro de la sociedad, Amorrortu, Buenos Aires.

Parsons, T. (1971): The System of modern societies, Englrwood Cliffs, Prentice Hall.

Pérez, C. (2004): Revoluciones tecnológicas y Capital Financiero, Ed. Siglo XXI, México-Buenos Aires.

Porter, M. E. (1990): The Competitive Advantage of Nations, The Macmillan Press, London y Basingstoke.

Reich, R. (1993): El trabajo de las naciones. Hacia el capitalismo del si- glo XXI, Vergara Editores, Buenos Aires.

Reinert, H. y Reinert, E. (2011): "La destrucción creativa en Economía: Nietzsche, Sombart, Schumpeter", en ¿Puede sobrevir el capitalismo?, Capitán Swing, Madrid.

Revista Ekonomiaz (2009): N. ${ }^{\circ}$ 70, Sistemas Regionales de Innovación.

Robertson, R. (2004): Las Tres Olas de la Globalización, Alianza, Madrid.

Rodrik, D. (1997): Has globalization gone too far?, Institute for International Economics, Washington.

Rodrik, D. (2003): The global governance of trade as if development really mattered, en www.undp.org/bdp, Free trade optimism, Foreign Affairs.

Rostow, W. (1993): Las etapas del crecimiento económico, Ministerio de Trabajo, Madrid.

Sartori, G. (1993): La democracia después del comunismo, Alianza, Madrid.

Sassen, S. (1999): La Ciudad Global, FCE, Buenos Aires.

Sassen, S. (2003): Los Espectros de la Globalización, FCE, Buenos Aires.

Sassen, S. (2007): Una Sociología de la Globalización, Katz, Buenos Aires.
Saxenian, Anna Lee (2007): The New Argonauts. Regional Advantage in a Global Economy, Harvard University Press.

Sennett, R. (2000): La Corrosión del Carácter, Anagrama, Barcelona.

Sennett, R. (2006): La cultura del nuevo capitalismo, Anagrama, Barcelona.

Smelser, N. (1962): Theory of collective behavior, Free Press, Nueva York.

Soja, A. (2008): Postmetrópolis, Mapas, Madrid.

Sztompka, P. (1995): Sociología del Cambio Social, Alianza, Madrid.

Van Den Berg, Leo; Pol, P. M.; Van Winden, W. y Woets, P. (2005): European Cities in the Knowledge Economy, Aldershot, Ashgate.

Von Hippel, E. (1988): The sources of innovation, New York, Oxford Univ. Press.

Von Hippel, E. (2005): Democratizing Innovation, Cambridge, MA: MIT Press.

Weber, Max (1969): La Ética puritana y el espiritu del Capitalismo, Península, Barcelona, 1. ${ }^{\text {a ed. }}$

Winden, W.; Van der Berg, L. y Pol, P. (2007): "European Cities in the Knowlwdge Economy: Towards a Typology", Urban Studies, vol. 44. 